\title{
Addenda and Corrigenda to
}

An Axiomatic Definition of the Programming Language PASCAL

\author{
C. A. R. Hoare and N. Wirth
}

Acta Informatica 2, 335-355 (1973).

p. 336 The first published suggestion of an axiomatic method in language definition occurs in

Floyd, R. W. Assigning meanings to programs. Proc. Symposia in Applied Mathematics 19. Providence (R. I.): Amer. Math. Soc. 1967, p. 19-32.

p. 342 Axiom 5.3 does not apply exactly to variant records: it should be replaced by

5.3a. $T\left(x_{1} \ldots x_{m-1}, k_{j}, x_{j}^{\prime}\right) . \quad s_{i}=x_{i} \quad$ for $\imath=1 \ldots m-1$.

p. 342 line 14 for $s_{j}$ read $s_{j}^{\prime}$.

The authors would like to take this opportunity of expressing their gratitude to Prof. E. Engeler and Stein Krogdahl, for valuable comments on an earlier draft. 